\title{
The course of multiple sclerosis rewritten: a Norwegian population-based study on disease demographics and progression
}

\author{
Cecilia Smith Simonsen ${ }^{1,3,4} \cdot$ Heidi Øyen Flemmen ${ }^{2,5} \cdot$ Line Broch $^{1,3,4} \cdot$ Cathrine Brunborg $^{6} \cdot$ Pål Berg-Hansen $^{3}$. \\ Stine Marit Moen ${ }^{7}$. Elisabeth Gulowsen Celius ${ }^{3,4}$
}

Received: 3 August 2020 / Revised: 13 October 2020 / Accepted: 14 October 2020 / Published online: 22 October 2020

(C) The Author(s) 2020

\begin{abstract}
Objectives Over the past few decades, there has been an improvement in the rate of disability progression in multiple sclerosis (MS) patients, and most studies relate this evolvement to the introduction of disease-modifying therapies. However, several other factors have changed over this period, including access to MRI and newer diagnostic criteria. The aim of this study is to investigate changes in the natural course of MS over time in a near-complete and geographically well-defined population from the south-east of Norway.

Methods We examined disease progression and demographics over two decades and assessed the effect of disease-modifying therapies using linear mixed-effect models.

Results In a cohort of 2097 patients, we found a significant improvement in disability as measured by the Expanded Disability Status Scale (EDSS) stratified by age, and the improvement remained significant after adjusting for time on diseasemodifying medications, gender and progressive MS at onset. The time from disease onset to EDSS 6 in the total cohort was 29.8 years (95\% CI 28.5-31.1) and was significantly longer in patients diagnosed after 2006 compared to patients diagnosed before. There are significant differences between patient demographics, as well as time to EDSS 6, in the near-complete, geographically well-defined population compared to an additional cohort from the capital Oslo and its suburbs.

Conclusion The natural course of MS is improving, but the improvement seen in disease progression has multifaceted explanations. Our study underlines the importance of completeness of data, relevant timeframes and demographics when comparing different MS populations. Studies on incomplete populations should be interpreted with caution.
\end{abstract}

Keywords Multiple sclerosis · Disease course $\cdot$ Natural history $\cdot$ Epidemiology $\cdot$ Time to EDSS 6

Electronic supplementary material The online version of this article (https://doi.org/10.1007/s00415-020-10279-7) contains supplementary material, which is available to authorized users.

Cecilia Smith Simonsen cecsim@ vestreviken.no

1 Department of Neurology, Vestre Viken Hospital Trust, Dronninggata, 3004 Drammen, Norway

2 Department of Neurology, Hospital Telemark HF, Skien, Oslo, Norway

3 Department of Neurology, Oslo University Hospital, Oslo, Norway

\section{Introduction}

In 1989, the median time from onset of multiple sclerosis (MS) to dependence on a walking aid, Expanded Disability Status Scale (EDSS) 6, was 15 years [1]. Several studies have confirmed a delay in the time to reach EDSS 6 over the past two decades [2,3]. Most studies attribute this delay to the effects of disease-modifying treatments (DMTs) $[2,4,5]$.

4 Institute of Clinical Medicine, University of Oslo, Oslo, Norway

5 Institute of Health and Society, University of Oslo, Oslo, Norway

6 Oslo Centre for Biostatistics and Epidemiology, Research Support Services, Oslo University Hospital, Oslo, Norway

7 MS-Centre Hakadal, Grønvoll, Norway 
Much has changed in addition to the introduction of DMTs, including an increase in the global prevalence and incidence of MS [6], revised diagnostic criteria [7] and a possible decrease in the diagnosis of primary progressive MS $[8,9]$. Patients more frequently have a less severe disease course and a larger proportion of patients are female [10]. The composition of previous natural history cohorts may, therefore, be of limited relevance as a reference for today's patients. In addition, recent studies are usually based on large, multicenter databases such as MSBase [11] and national MS registries [12], which rarely represent a complete population [13]. The translatability of these studies to the general MS population is consequently under scrutiny [14]. The aim of this study is to investigate changes in the natural course of MS over time in a complete and geographically well-defined population.

\section{Materials and methods}

\section{Population}

This is a registry-based study. The Buskerud-Oslo-Telemark (BOT) registry contains information on patients diagnosed with MS between 1919 and 2017 in the two regional hospital trusts of Vestre Viken Health Trust (VVHF), with patients mostly from the county of Buskerud, and Telemark Hospital Trust (STHF), as well as in Oslo University Hospital (OUS). These hospitals serve a population of 1.17 million people (490 000, 170000 and 510000 respectively) in south-eastern Norway (Fig. 1). The neurological departments at VVHF and STHF serve as the main MS clinics for their populations, and the complete populations from these counties are included. The Oslo population is an incomplete, but a historically unique university MS registry in Norway. Some patients were transferred to another hospital in 2010 due to regional reorganization, and some were lost to follow-up.

All Norwegian citizens have a national identity number that allows for the unique identification of patients. During the study period, every MS patient in Norway and their

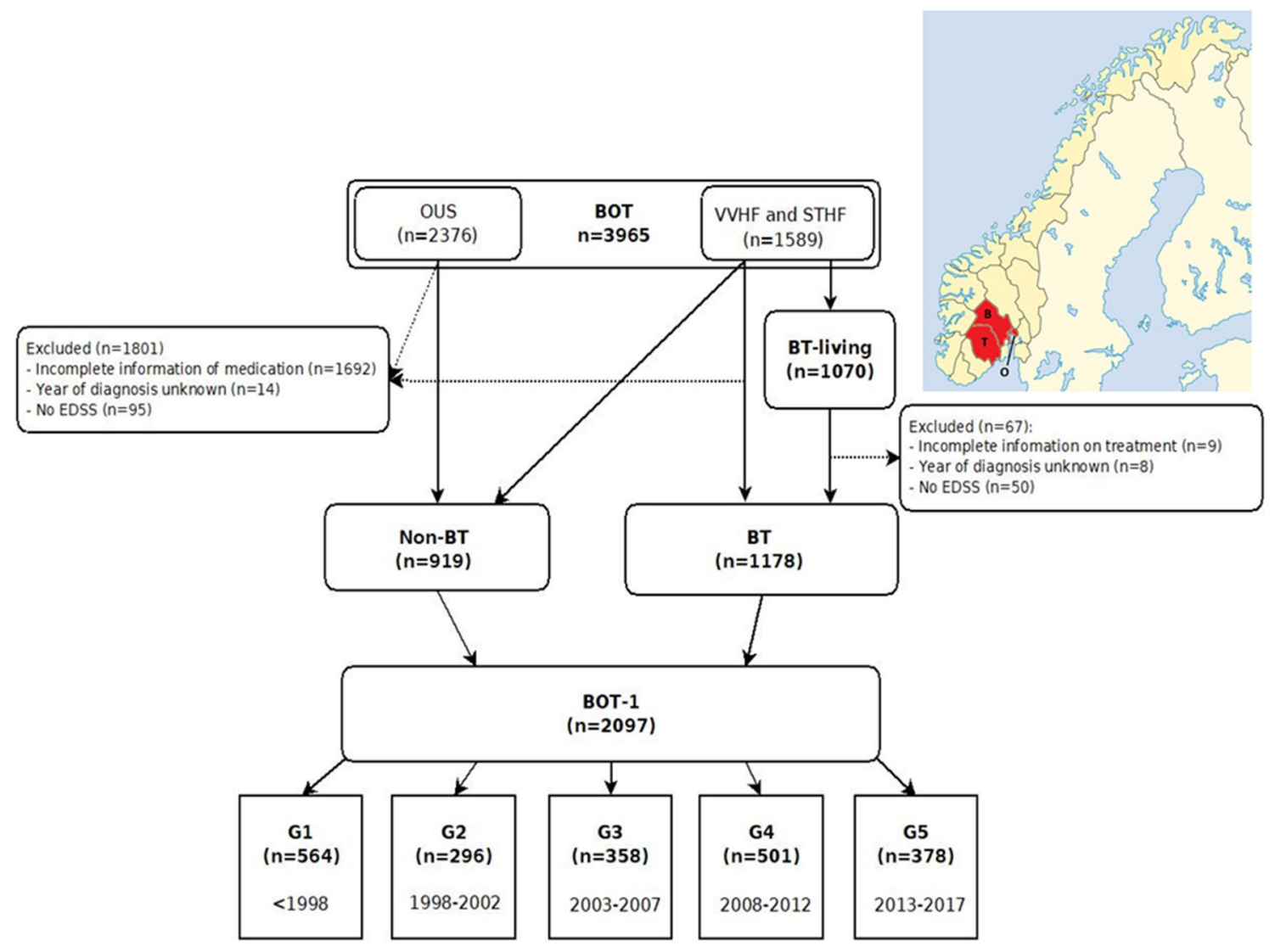

Fig. 1 Flow diagram of population with a map of Norway denoting the counties of Buskerud (B), Telemark (T) and Oslo (O) in red (courtesy of Kartverket) 
neurologists had access to all DMTs available since market access in Europe. Almost all patients with MS are followed by neurologists at public hospitals, and there are few neurologists in private practice.

\section{Methods}

We did a search for the ICD-10 diagnosis G35 (MS) in the three hospitals' electronic medical system in January 2018. All patients were diagnosed according to the prevailing diagnostic criteria at the time [7]. Three experienced MS specialized neurologists examined all medical journals and retrospectively documented information on the disease. They followed predetermined criteria and discussed challenging cases in the group to limit sampling bias.

Disease onset was defined as the time of the first symptom suggestive of MS, type of main symptom based on Kurtzke's functional systems [15] and whether one or more than one system was affected. We documented time of diagnosis, number of relapses before diagnosis, phenotype, oligoclonal bands and EDSS. Year of death was registered where appropriate.

We documented information on DMTs, including time of start and discontinuation. Only treatments used for at least three months were included. We considered natalizumab, fingolimod, alemtuzumab, mitoxantrone, rituximab and autologous hematopoietic stem cell therapy as highly efficacious DMTs. All induction therapies (mitoxantrone, alemtuzumab, autologous hematopoietic stem cell transplantation) were considered effective from the first dose until the end of observation.

The patients were divided into five subgroups: G1 (diagnosed $\leq 1997)$, G2 (1998-2002), G3 (2003-2007), G4 (2008-2012) and G5 (2013-2017). G2 is the first group with complete case attainment and the group diagnosed prior to introduction of the first more efficacious DMT, natalizumab, in 2006 [16]. G2 was, thus, used as a comparator for the first group diagnosed after the introduction of more efficacious DMTs and with sufficient time for follow-up, G4. We also compared the populations diagnosed before and after 2006.

\section{The different cohorts}

From the BOT database, we have constructed two main cohorts: (1) "BT-living" is the geographically complete and living population from Buskerud and Telemark, which was used for calculating incidence and prevalence. (2) "BOT-1" contains all living and dead patients from BOT with complete information on diagnosis, treatment and at least one EDSS, regardless of residence. BOT-1 was further divided into five subgroups based on year of diagnosis and was used for the calculations of disease progression (Fig. 1). We have also divided the BOT-1 population into "BT" and "NonBT", with the latter only encompassing patients residing outside the geographically well-defined area of Buskerud and Telemark on 1st January 2018 or at time of death. Non-BT mostly includes patients from the Oslo-region.

\section{Time to EDSS}

We considered all recorded EDSS scores, except those assessed within three months after a relapse. If there was no EDSS, but sufficient information available, an EDSS score was constructed. All three researchers obtained Neurostatus certification before data collection [17].

To calculate time to EDSS 6, we included all patients who had reached EDSS 6 and where we knew the year of EDSS 6. We also included those with an updated EDSS in the past 2 years $(n=1702)$ and patients with a known EDSS below four in the last 6 years $(n=180)$. All remaining patients were excluded either due to lack of information on year of onset, uncertainty whether they have reached EDSS 6 or unknown year of reaching EDSS 6. This approach excludes patients with an EDSS 4-5.5 at last clinic visit 3-6 years ago $(n=9)$, who have a high probability of progressing to EDSS 6 in the study period.

\section{Statistics}

All data were collected in EpiData and transferred to IBM SPSS Statistics 25.0 (IBM Corp., Armonk, NY, USA) and Stata 15 (Stata Corp. LLC,College Station, TX, USA). The crude prevalence was estimated based on prevalent MS cases in BT-living on January, 1st 2018. The denominator was the total population of Buskerud and Telemark $(n=455160$; Statistics Norway, www.ssb.no/tabell/07459). Annual incidence rates were calculated based on new MS cases between 1998 and 2017, divided by the estimated population at risk. The results are presented as incidence rates (new cases per 100000 person-years) with 95\% confidence intervals (CI). The Wilson $95 \%$ CI was calculated for both prevalence and incidence using www.openepi.com. We used the 2013 European standard population for adjustment of incidence and prevalence. Patient years is defined as total number of years from diagnosis to 1st January 2018, death or lost to follow-up.

Differences in continuous variables between two groups were assessed by independent sample $t$ test, i.e., BT vs Non-BT and before vs. after 2006. The Chi square test for contingency tables was used to detect associations between categorical variables. One-way ANOVA was used to compare means across the five subgroups. Linear mixed-effects models were used to investigate the EDSS progression between the five groups over the follow-up period, and to account for repeated measures. Age at EDSS was used as the 
time variable, and all the analyses were stratified on cohort (BOT-1, BT, and Non-BT). In the models, time, time by group interaction and covariates were treated as fixed effects. All models included a random intercept, and an unstructured covariance matrix. The Kaplan-Meier method was used to estimate time to EDSS 6, and Log-Rank test was used to compare groups. Follow-up time was calculated as person-years from time of onset until the date of EDSS 6, date of emigration, death or to January 1st, 2018, whichever occurred first. All $p$ values were two-sided and a 5\% significance level was used.

\section{Ethics and data availability}

The Regional Ethics Committee in Norway approved this study (REK 2015/670). Specific requests regarding data sharing should be directed to the corresponding author.

\section{Results}

\section{Prevalence and incidence}

In the prevalent MS population of BT-living, 1070 patients were alive and residing in these two counties on date of prevalence, which corresponds to a crude prevalence of 235.1/100 000 (95\% CI 221.3-249.7). The prevalence adjusted to the European standard population was 237.4/100 000 (95\% CI 223.3-251.6). The gender ratio was 2.1:1 with a female predominance, which did not change significantly over the two decades.

1032 patients were diagnosed between 1998 and 2017. This gives a mean yearly incidence of $12.3 / 100000$ (95\% CI 11.5-13.0). The incidence adjusted to the European Standard population was 12.2/100 000 (95\% CI 11.5-13.0). The incidence increased from 10.7/100 000 (95\% CI 9.8-11.6) in the period 1998-2009 to $14.4 / 100000$ (95\% CI 13.1-15.6) in the period 2010-2017.

\section{The population}

Of a total of 3965 patients in BOT, comprehensive information on 2097 patients in the BOT-1 cohort was available, which is the equivalence of 27916 patient years (Fig. 1). G1 lost $30.1 \%$ of its population to follow-up, either due to death or relocation. G2 lost 19.9\%, G3 lost 12.6\%, G4 lost $5.4 \%$ and G5 lost $1.3 \%$. We included $93.7 \%(n=1003)$ of the complete BT-living population from Buskerud and Telemark. Demographic information on the subgroups is shown in Table 1.

We found a significant difference between the proportion of older patients ( $\geq 50$ years) at disease onset $(p<0.001)$ and at diagnosis $(p<0.001)$ before and after 2006 (Fig. 2).
Patients who were $\geq 50$ years and diagnosed after 2006 had a disease onset 3.0 years later $(p<0.001)$, were diagnosed 1.7 years later $(p=0.001)$ and had a 0.3 point lower EDSS score $(p=0.05)$ compared to those diagnosed before 2006 .

\section{The disease course}

The mean time from onset to EDSS 6 was 29.8 (95\% CI 28.5-31.1) years (Fig. 3). A total of 692 patients (33.0\%) had reached EDSS 6, and 1319 (62.9\%) had not reached EDSS 6. However, 86 patients who had reached EDSS 6, and 40 patients who had not reached EDSS 6, were excluded due to lack of information on year of onset or year of EDSS 6 . Table 2 shows time to EDSS 6 in the different subgroups.

The results from the linear mixed-effects models investigating the EDSS progression over the entire follow-up period are presented in Table 3. Using patients diagnosed between 1998 and 2002 (G2) as a reference, there is a significant delay in EDSS progression by age compared to patients diagnosed between 2008 and 2012 (G4) within all three cohorts (BOT-1: $p<0.001$, BT: $p<0.001$, nonBT: $p=0.002)$. After adjusting for months treated with any DMT, age at onset, gender and progressive MS at onset, this improvement remained highly significant (Fig. 4, Table 3). Adjusting for time on highly active DMT did not alter the outcome.

We divided the population into "progressive at onset" and "relapsing at onset" and looked at the disease progression in the two separate groups. In our progressive patients, we did not find significant differences between the reference group (G2, diagnosed 1998-2002) and patients diagnosed after 2002, neither before nor after adjustment (treatment, age at onset and gender). Our findings in the relapsing group emulated the population as a whole, both before and after adjustment (supplementary tab 1 and supplementary fig 1 ).

\section{BT vs. Non-BT}

Non-BT patients $(n=919)$ were younger than the geographically defined, near-complete BT population $(n=1178)$ at prevalence date. See Table 4 for demographic differences. The main findings of differences in EDSS progression in the five subgroups remained the same, both before and after adjustment, in both cohorts (supplementary Table 2). There was, however, a significant difference in time from onset to EDSS $6(p=0.001)($ Table 2$)$.

\section{Discussion}

There is significant delay in the EDSS progression stratified by age between patients diagnosed in 1998-2002 and patients diagnosed in 2008-2012. The difference remained 
1334

Journal of Neurology (2021) 268:1330-1341

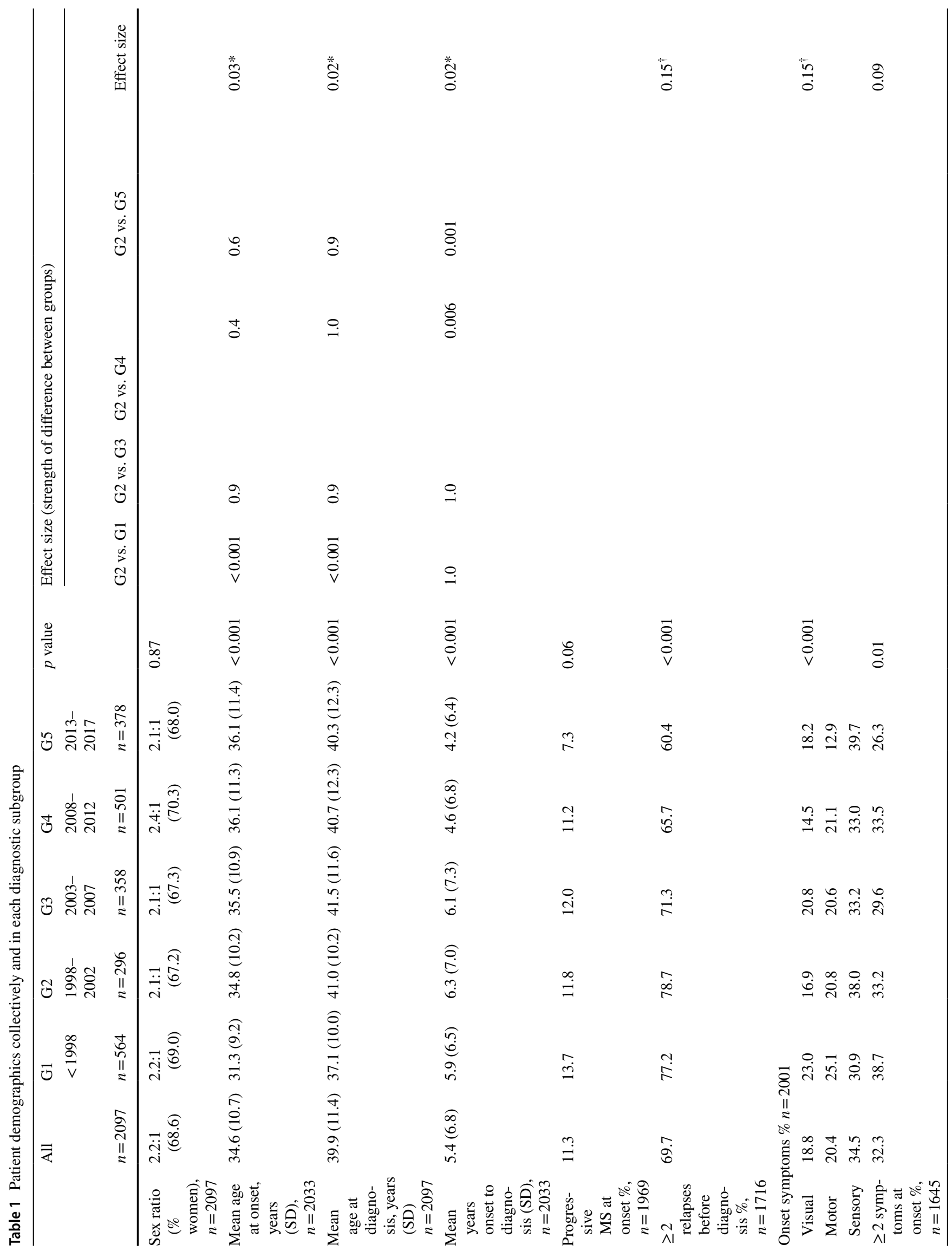

Springer 


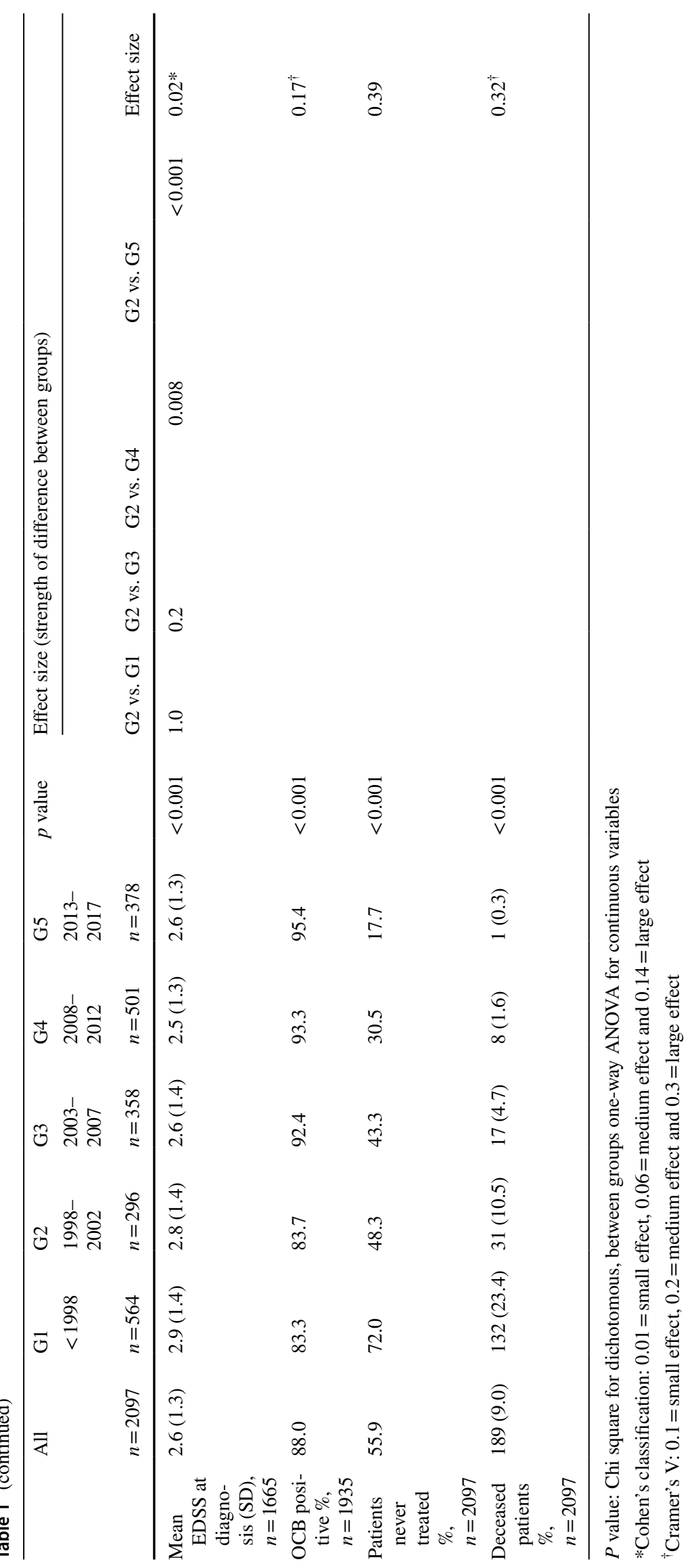




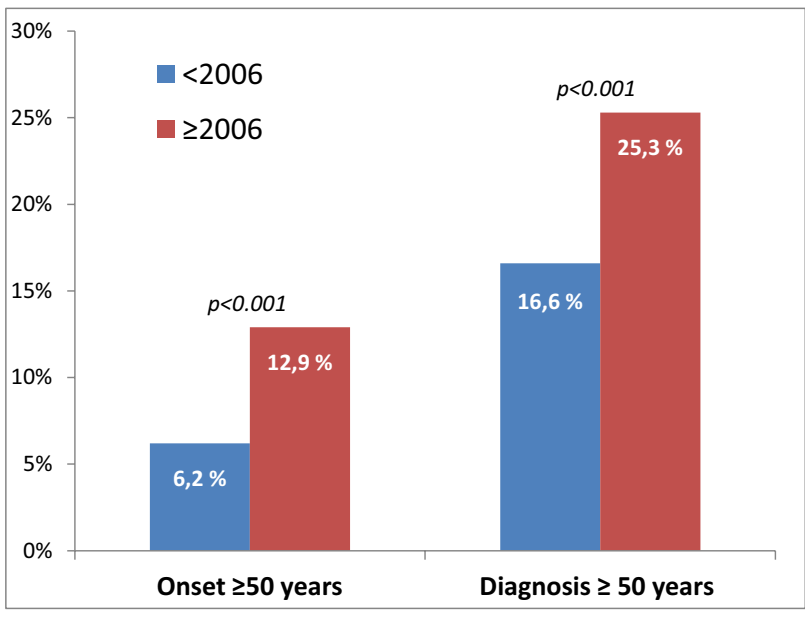

Fig. 2 The proportion of older patients ( $\geq 50$ years) at disease onset $(p<0.001)$ and at diagnosis $(p<0.001)$ before and after 2006

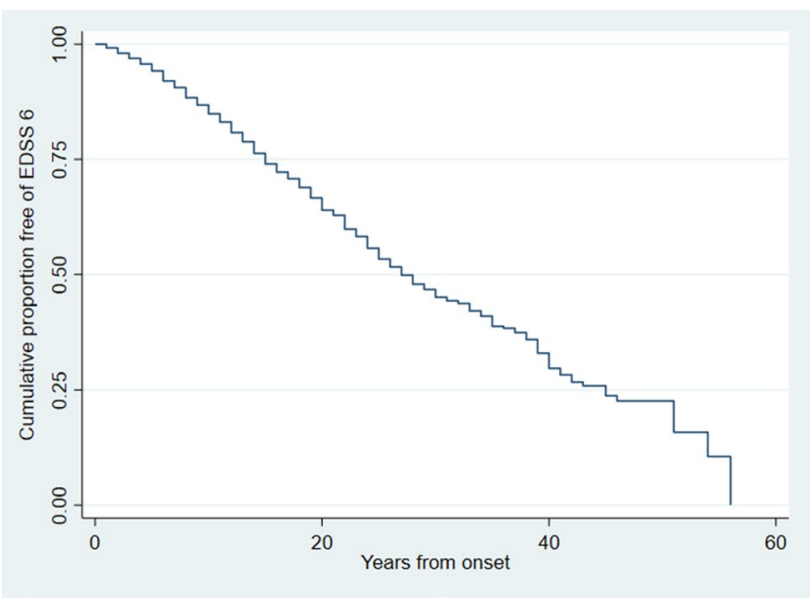

Fig. 3 Kaplan-Meier estimate of time from onset to EDSS 6

significant after adjusting for the number of months on treatment with DMTs. The delay in disease progression found in this near-complete, geographically well-defined MS population has several explanations, which is supported by our findings that the population demographics have also changed significantly over the past two decades.

Several studies have reported that the natural history of multiple sclerosis is changing, many of which conclude that all or most of this improvement can be attributed to the introduction of DMTs [4, 18-21]. However, the slowing in disease progression seems to have started even before the introduction of DMTs [22].

Meanwhile, prevalence and incidence of MS has increased over the past decades [6]. The prevalence in our population in 2018 was $231.8 / 100000$, which is an increase
Table 2 Means for time to EDSS 6 in five subgroups, patients diagnosed before or after 2006 and BT vs. Non-BT patients

\begin{tabular}{|c|c|c|c|c|}
\hline & $\begin{array}{l}\text { Years to } \\
\text { EDSS } 6\end{array}$ & $95 \% \mathrm{CI}$ & $\begin{array}{l}\text { Reached } \\
\text { EDSS } \\
6 \%\end{array}$ & $p$ value \\
\hline BOT-1 & 29.8 & $28.4-31.1$ & 34.5 & \\
\hline BT-living & 30.4 & $28.5-32.4$ & 31.2 & \\
\hline G1 $($ diagnosed $\leq 1997)$ & 26.7 & $25.0-28.5$ & 70.5 & $<0.001$ \\
\hline G2 (1998-2002) & 25.9 & $23.5-28.3$ & 48.5 & \\
\hline G3 (2003-2007) & 31.5 & $28.2-34.8$ & 31.3 & \\
\hline G4 (2008-2012) & 36.0 & $31.6-40.4$ & 12.7 & \\
\hline G5 (2013-2017) & 42.8 & $36.6-49.1$ & 3.7 & \\
\hline $\begin{array}{l}\text { Patients diag- } \\
\text { nosed }<2006\end{array}$ & 27.6 & $26.2-29.0$ & 57.8 & $<0.001$ \\
\hline $\begin{array}{l}\text { Patients diag- } \\
\text { nosed } \geq 2006\end{array}$ & 35.3 & $32.0-38.6$ & 12.3 & \\
\hline BT patients & 27.3 & $25.8-28.9$ & 40.4 & $<0.001$ \\
\hline Non-BT patients & 33.8 & $31.6-35.9$ & 26.7 & \\
\hline Relapsing at onset & 32.2 & $30.7-33.7$ & 27.1 & $<0.001$ \\
\hline Progressive at onset & 13.9 & $12.1-15.7$ & 70.3 & \\
\hline \multicolumn{5}{|l|}{ Progressiv at onset } \\
\hline G1 (diagnosed $\leq 1997)$ & 12.0 & $9.6-14.4$ & 96.8 & 0.04 \\
\hline G2 (1998-2002) & 10.8 & $8.5-13.1$ & 87.9 & \\
\hline G3 (2003-2007) & 11.1 & $8.6-13.6$ & 74.3 & \\
\hline G4 (2008-2012) & 19.5 & $14.0-25.0$ & 46.3 & \\
\hline G5 (2013-2017) & 17.2 & $11.0-17.0$ & 29.6 & \\
\hline
\end{tabular}

BOT-1 database of all 2097 patients from Buskerud, Oslo and Telemark included in study, BT-living: geographically complete and living population from Buskerud and Telemark, BT Buskerud and Telemark, Non-BT everyone in BOT-1 who does not reside in Buskerud or Telemark, $C I$ confidence interval

from 213.8/100 000 (only Buskerud) in just 4 years [23]. We also observed an increase in the incidence.

There are many reasons for the apparently milder course of disease progression [24]. While this study only spans two decades, our findings demonstrate the rapid change in MS demography over time. We are now diagnosing patients earlier in the disease and our data show that more patients with MS have a less severe disease course. Our findings are significant, and in line with other studies [24-26]. The MS population is changing, and one of the most obvious reasons is the honing of the diagnostic criteria from Schumacher via Poser to McDonald [7, 27-31]. Between 1965 and 2001, the diagnosis of relapsing MS was based on at least two relapses from two or more parts of the CNS. It is now possible to diagnose MS based on one relapse and a single MRI examination. The change in population characteristics due to change in diagnostic criteria is known as the Will Rogers phenomenon, and can lead to perceived improvements in prognosis, even though the outcome of individual patients has not changed [32]. 
Table 3 Results from linear mixed-effects regression analyses (unadjusted and adjusted) of EDSS progression over time

\begin{tabular}{|c|c|c|c|c|c|c|c|}
\hline \multirow[t]{4}{*}{ Group } & \multirow[t]{4}{*}{ Year of diagnosis } & \multicolumn{3}{|c|}{ Unadjusted } & \multicolumn{3}{|c|}{ Adjusted } \\
\hline & & \multicolumn{3}{|l|}{ BOT-1 } & \multicolumn{3}{|l|}{ BOT-1 } \\
\hline & & \multicolumn{3}{|c|}{$(n=13075$ EDSS $)$} & \multicolumn{3}{|c|}{$(n=12713$ EDSS $)$} \\
\hline & & Coef & $95 \% \mathrm{CI}$ & $p$ value & Coef & $95 \% \mathrm{CI}$ & $p$ value \\
\hline \multicolumn{2}{|l|}{ Age at EDSS } & 0.144 & $0.130-0.159$ & $<0.001$ & 0.148 & $0.134-0.163$ & $<0.001$ \\
\hline $\mathrm{G} 2$ & 1998-2002 & \multicolumn{3}{|l|}{ Reference } & & & \\
\hline \multicolumn{8}{|c|}{ Diagnostic group } \\
\hline G1 & $<1998$ & 1.863 & $1.028-2.552$ & $<0.001$ & 1.739 & $0.912-2.567$ & $<0.001$ \\
\hline G3 & 2003-2007 & 0.626 & $-0.300-1.552$ & 0.19 & 0.580 & $-0.327-1.487$ & 0.21 \\
\hline G4 & 2008-2012 & 2.516 & $1.607-3.424$ & $<0.001$ & 2.311 & $1.415-3.207$ & $<0.001$ \\
\hline G5 & 2013-2017 & 3.464 & $2.371-4.558$ & $<0.001$ & 2.462 & $1.372-3.552$ & $<0.001$ \\
\hline \multicolumn{8}{|c|}{ Diagnostic group by age of EDSS (interaction term) } \\
\hline G1 & $<1998$ & -0.02 & -0.036 to -0.0003 & 0.05 & -0.021 & $-0.040--0.003$ & 0.02 \\
\hline G3 & 2003-2007 & -0.020 & $-0.036-0.0004$ & 0.07 & -0.017 & $-0.038-0.003$ & 0.09 \\
\hline G4 & 2008-2012 & -0.072 & -0.092 to -0.052 & $<0.001$ & -0.065 & $-0.085--0.045$ & $<0.001$ \\
\hline G5 & 2013-2017 & -0.099 & -0.124 to -0.074 & $<0.001$ & -0.070 & $-0.096--0.045$ & 0.001 \\
\hline Intercept & & -3.503 & -4.181 to -2825 & $<0.001$ & -1.505 & $-2.309-0.701$ & $<0.001$ \\
\hline
\end{tabular}

Adjusted for months spent on all disease-modifying treatment, progressive MS at onset, age at onset and gender. BOT-1: database of all 2097 patients from Buskerud, Oslo and Telemark included in study

Coef regression coefficient, EDSS expanded disability status scale

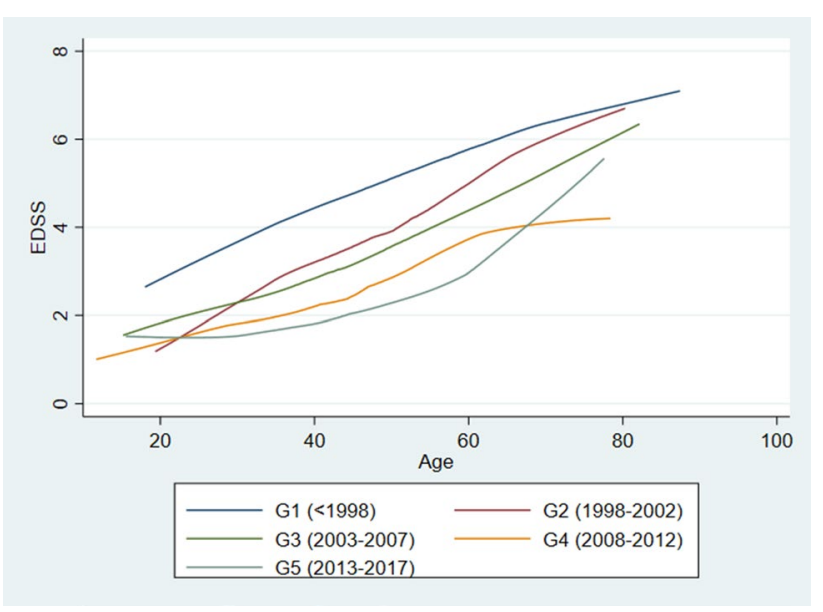

Fig. 4 EDSS progression in five diagnostic groups, adjusted for months on all treatment, gender, progressive MS at onset and age at onset

In addition, we are more likely to diagnose older patients. According to the Schumacher criteria, a patient could only be diagnosed with MS if they were younger than 50 years of age [27]. In our population, a quarter of the patients diagnosed in or after 2006 were 50 years or older at the time of diagnosis. We see a steady increase in mean age at onset and diagnosis across the five subgroups. Historically, many older patients would be diagnosed with an undefined neurodegenerative disease before the introduction of MRI [33] or remained undiagnosed [34]. Patients with few symptoms would previously have been assigned a non-specific diagnosis [35]. Our data show that fewer patients have motor symptoms at onset after 2006 compared to historical patients, again supporting the notion of a milder disease [36, 37].

As time passes, the general population has more access to neurologists and MRI machines. The ratio of neurologists per capita in Norway has doubled since 1995 from 4.8/100 000 to 9.5/100 000 in 2017 (data from The Norwegian Doctors' Union). In 1989, the BMJ published an article by McDonald explicitly advising physicians to only recommend investigating patients presenting with symptoms of MS "when it is clear to the patient that there is something that needs explanation" [38]. Today, we urge primary care doctors to "refer to a neurologist urgently" if they suspect MS, to ensure a prompt diagnosis and initiation of diseasemodifying treatment [39].

In addition to the changing demographics of the MS population, there is an increasing amount of data from experimental and clinical trials indicating that exercise can modify the projection of MS [40]. And multiple sclerosis is certainly not the only disease showing a decline in late-life disability. There are documented drops in late-life disability from cardiovascular disease, musculoskeletal conditions, infectious diseases and cancers [41, 42] compared to the 1980s and 1990s, the timing of which corresponds to the improvements in surgical techniques and pharmacological treatments, as well as changes in socioeconomic and lifestyle factors [43]. 
Table 4 Comparison of patients in BT and Non-BT patients collectively, as well as before and after 2006

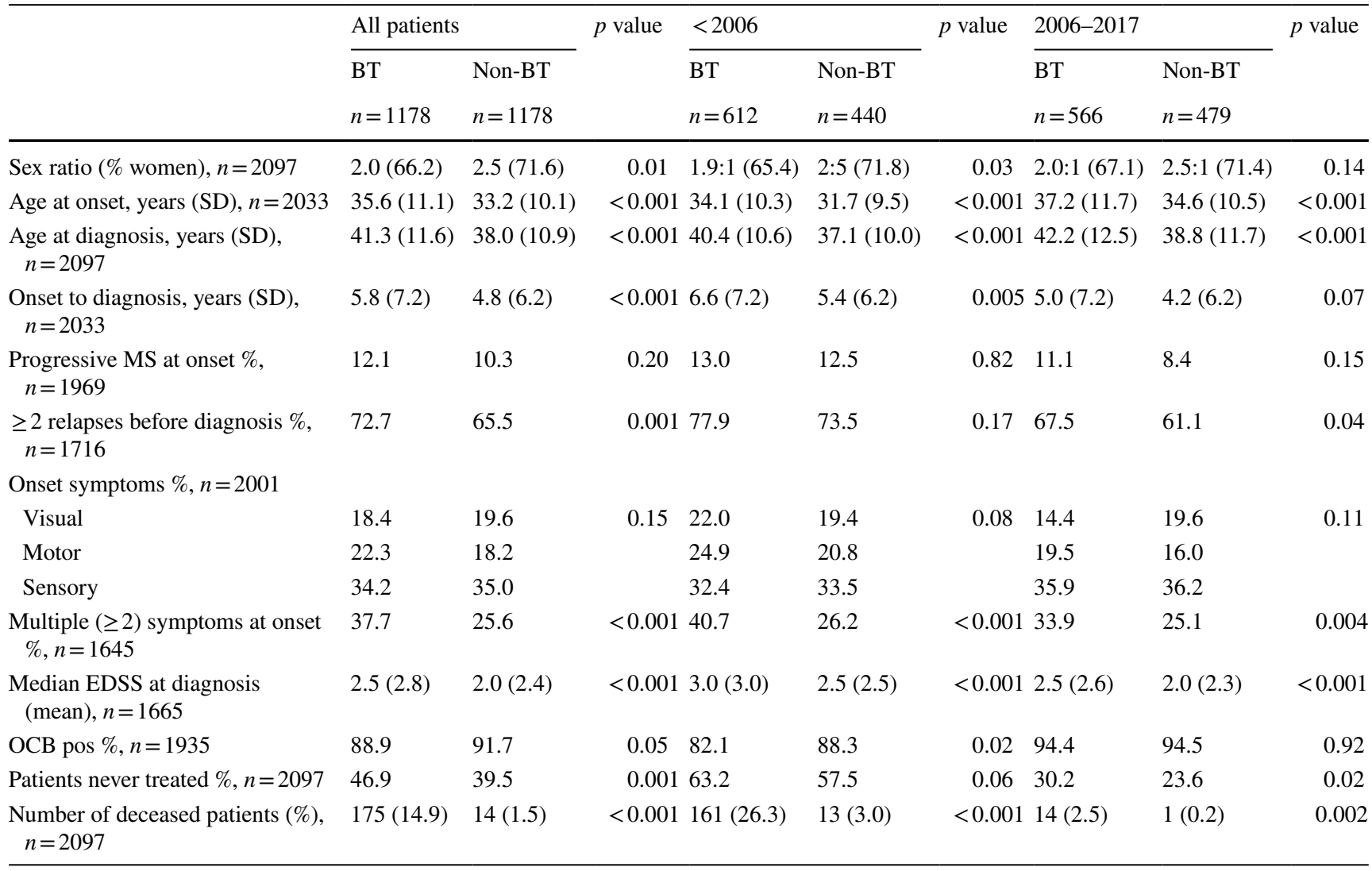

$p$ value: Independent-sample $t$ test for categorical, Chi square for dichotomous

$B T$ Buskerud and Telemark, Non-BT everyone in BOT-1 who does not reside in Buskerud or Telemark, $S D$ standard deviation, EDSS expanded disability status score, $O C B$ pos oligoclonal bands positive

Smoking has been implicated in the progression of multiple sclerosis [44], but after a concerted effort by governments in the developed world to protect the public from the dangers of tobacco through anti-smoking advertisement, taxes and banning smoking in public spaces, we have seen a decline in the number of smokers in the West [45, 46]. According to Statistics Norway, the percentage of daily smokers above 16 years of age has fallen from 33\% in 1998 to $12 \%$ in 2018. In addition, numerous observational studies have suggested that there is a correlation between the level of serum vitamin D and disease activity [47], and there has been an increasing focus on vitamin D status supplements [48]. Like us, most studies on disease progression of MS do not register or correct for these factors. Thus, the possible influence of these factors on disease progressions remains unknown.

All these factors combined evidently cause a reduction in time from onset to diagnosis and less severe disease. Subsequently, historical cohorts have likely been enriched with severe MS cases. An illustrative example of this is the changing characteristics of the placebo patients in randomized controlled trials [49]. The annualized relapse rate in the first year after treatment for the placebo groups in the
AFFIRM trial from 2006 [16] and CLARIFY from 2010 [50] was 0.81 and 0.33 respectively. The first interferon trials reported a $30 \%$ reduction in annual relapse rate (ARR) compared to placebo [51], and the newer disease-modifying drugs halved the ARR compared to placebo 10 years later $[16,52]$. However, as our findings demonstrate, MS populations 10 years apart are not the same and real-world studies comparing older drugs in historical cohorts with newer drugs should be interpreted with caution [53].

Contrary to the majority of other studies on disease course, we have limited selection bias and know who is missing and why. The prevalent population includes all MS patients in the two counties of Buskerud and Telemark (BT), and is near-complete. There will always be patient leakage for one reason or another, but this is negligible in our study, due to geographical considerations and the setup of the health care system. To our knowledge, this is the most complete MS registry of a geographically well-defined population.

We did not find a similarly significant improvement in EDSS progression stratified by age in the progressive only group, though we did find a significant improvement in time 
to EDSS 6 for progressive patients in the five subgroups. However, these numbers are small and should be interpreted with caution. And although the changes in EDSS despite DMTs remained, in most part, the same between the complete BT population and the non-BT population, we did find a difference in time to EDSS 6 . In addition, there are some significant differences as the non-BT population includes the Oslo region biased towards younger, more educated, wealthier and more treated patients than the rest of our population. This is in itself an important finding and raises concern as to the generalizability of non-population-based studies. The incomplete non-BT was, therefore, interesting for comparison since many heavily cited papers that are applauded for their size either have a population stemming from tertiary, often university-based MS clinics in larger cities [11, 18], or incomplete populations [2, 3].

The retrospective study design entails investigator bias and missing data. This was ameliorated by the fact that only three MS specialists have included data based on a mutually accepted manual. However, even in our near-complete, prevalent BT population, we had to exclude 78 patients due to missing information on date of diagnosis, EDSS or treatment. The non-BT population was an arbitrary collection of patients in the Oslo region, not unlike patients in large registries. In addition, we cannot rule out a small amount of informative censoring in which patients diagnosed before 1998 may be lost to follow-up. These patients are either severely disabled or have a very "benign" disease. We believe this to be an insignificant number considering the nature of our health care system. There is some uncertainty with regards to time to EDSS 6 as we only included $89.9 \%$ of the BOT-1 population and $86.6 \%$ of the geographically complete prevalent population in our Kaplan Meier analysis. This may overestimate the time to EDSS 6 slightly, though our case ascertainment is still better than most registry-based studies on time to EDSS 6.

\section{Conclusion}

Our retrospective study over two decades of a modern, welldefined and thoroughly clinically characterized Norwegian MS population shows a significant delay in the EDSS progression stratified by age. However, significant improvement in disability is seen in all MS patients diagnosed after 2006 compared to patients diagnosed before, even after correcting for the effect of DMTs. Our findings emphasize the importance of taking the alterations in demographics, timeframe and completeness of population data and overall treatment into account when looking at changes in disease progression over time. Thus, historical cohorts are unsuitable for comparison in MS studies, and caution is required when comparing different MS populations.
Acknowledgments The BOT research group would like to thank all the patients in the BOT database, as well as our dedicated colleagues who have kept detailed notes on each patient and their disease throughout the past few decades.

Author contributions CSS Design and conceptualization; major role in the acquisition of data; analyzed and interpreted the data; drafted the manuscript for intellectual content. HØF Design and conceptualization; major role in the acquisition of data; interpreted the data; revised the manuscript for intellectual content. LB Design and conceptualization; major role in the acquisition of data; interpreted the data; revised the manuscript for intellectual content. CB Analyzed and interpreted the data; revised the manuscript for intellectual content. PB-H Design and conceptualization; interpreted the data; revised the manuscript for intellectual content. SMM Design and conceptualization; interpreted the data; revised the manuscript for intellectual content; supervision. EGC Design and conceptualization; interpreted the data; revised the manuscript for intellectual content; supervision, project administration.

Funding Open Access funding provided by University of Oslo (incl Oslo University Hospital). The study was supported by an unrestricted research grant from Sanofi-Genzyme.

Code availability Not applicable.

\section{Compliance with ethical standards}

Conflicts of interest CSS has received unrestricted research grant Novartis, advisory board and/or speaker honoraria Sanofi, Merck and Biogen Idec. HØF has received unrestricted research grant Biogen Idec and Novartis, advisory board and/or speaker honoraria Sanofi, Merck and Biogen Idec. LB has received an unrestricted grant from Sanofi Genzyme and advisory board honoraria from Merck. CB has no conflicts of interest. PBH has received advisory board and/or speaker honoraria from Novartis, UCB, Teva, Merck and Biogen Idec. SMM has no conflicts of interest. EGC has received unrestricted research grants (Novartis and Sanofi), advisory boards and/or speaker honoraria (Almirall, Biogen Idec, Merck, Roche, Novartis, Sanofi and Teva).

Ethical approval This study was approved by the Regional Ethics Committee in Norway (REK 2015/670).

Open Access This article is licensed under a Creative Commons Attribution 4.0 International License, which permits use, sharing, adaptation, distribution and reproduction in any medium or format, as long as you give appropriate credit to the original author(s) and the source, provide a link to the Creative Commons licence, and indicate if changes were made. The images or other third party material in this article are included in the article's Creative Commons licence, unless indicated otherwise in a credit line to the material. If material is not included in the article's Creative Commons licence and your intended use is not permitted by statutory regulation or exceeds the permitted use, you will need to obtain permission directly from the copyright holder. To view a copy of this licence, visit http://creativecommons.org/licenses/by/4.0/.

\section{References}

1. Weinshenker BG, Bass B, Rice GP, Noseworthy J, Carriere W, Baskerville J et al (1989) The natural history of multiple sclerosis: 
a geographically based study I Clinical course and disability. Brain J Neurol 112(1):133-146

2. Beiki O, Frumento P, Bottai M, Manouchehrinia A, Hillert J (2019) Changes in the risk of reaching multiple sclerosis disability milestones in recent decades: a nationwide population-based cohort study in Sweden. JAMA Neurol 76(6):665-671

3. Tremlett H, Paty D, Devonshire V (2006) Disability progression in multiple sclerosis is slower than previously reported. Neurology 66(2):172-177

4. Palace J, Duddy M, Lawton M, Bregenzer T, Zhu F, Boggild M et al (2019) Assessing the long-term effectiveness of interferonbeta and glatiramer acetate in multiple sclerosis: final 10-year results from the UK multiple sclerosis risk-sharing scheme. J Neurol Neurosurg Psychiatry 90(3):251-260

5. Kingwell E, Leray E, Zhu F, Petkau J, Edan G, Oger J et al (2019) Multiple sclerosis: effect of beta interferon treatment on survival. Br J Neurol 142(5):1324-1333

6. Stenager E (2019) A global perspective on the burden of multiple sclerosis. Lancet Neurol 18(3):227-228

7. Thompson AJ, Banwell BL, Barkhof F, Carroll WM, Coetzee T, Comi G et al (2018) Diagnosis of multiple sclerosis: 2017 revisions of the McDonald criteria. The Lancet Neurology 17(2):162-173

8. Westerlind H, Stawiarz L, Fink K, Hillert J, Manouchehrinia A (2016) A significant decrease in diagnosis of primary progressive multiple sclerosis: a cohort study. Multiple Sclerosis (Houndmills, Basingstoke, England) 22(8):1071-1079

9. Harding KE, Wardle M, Moore P, Tomassini V, Pickersgill T, Ben-Shlomo Y et al (2015) Modelling the natural history of primary progressive multiple sclerosis. J Neurol Neurosurg Psychiatry 86(1):13-19

10. Koch-Henriksen N, Thygesen LC, Stenager E, Laursen B, Magyari M (2018) Incidence of MS has increased markedly over six decades in Denmark particularly with late onset and in women. Neurology 90(22):e1954-e1963

11. Butzkueven H, Chapman J, Cristiano E, Grand'Maison F, Hoffmann M, Izquierdo G et al (2006) MSBase: an international, online registry and platform for collaborative outcomes research in multiple sclerosis. Multiple Sclerosis (Houndmills, Basingstoke, England) 12(6):769-774

12. Glaser A, Stahmann A, Meissner T, Flachenecker P, Horakova D, Zaratin P et al (2019) Multiple sclerosis registries in Europe - an updated mapping survey. Multiple Sclerosis Related Disord 27:171-178

13. Cohen JA, Trojano M, Mowry EM, Uitdehaag BMJ, Reingold SC, Marrie RA (2019) Leveraging real-world data to investigate multiple sclerosis disease behavior, prognosis, and treatment. Multiple Sclerosis J 26(1):23-37

14. Chen Z, Emberson J, Collins R (2019) Strategic need for large prospective studies in different populations. JAMA 2:56

15. Kurtzke JF (1983) Rating neurologic impairment in multiple sclerosis: an expanded disability status scale (EDSS). Neurology 33(11):1444-1452

16. Polman $\mathrm{CH}$, O'Connor PW, Havrdova E, Hutchinson M, Kappos L, Miller DH et al (2006) A randomized, placebo-controlled trial of natalizumab for relapsing multiple sclerosis. En J Med 354(9):899-910

17. D’Souza M, Yaldizli O, John R, Vogt DR, Papadopoulou A, Lucassen E et al (2017) Neurostatus e-scoring improves consistency of expanded disability status scale assessments: a proof of concept study. Multiple Sclerosis (Houndmills, Basingstoke, England) 23(4):597-603

18. Brown JWL, Coles A, Horakova D, Havrdova E, Izquierdo G, Prat A et al (2019) Association of initial disease-modifying therapy with later conversion to secondary progressive multiple sclerosis. JAMA 321(2):175-187
19. Claflin SB, Tan B, Taylor BV (2019) The long-term effects of disease modifying therapies on disability in people living with multiple sclerosis: a systematic review and meta-analysis. Multiple Sclerosis Related Disord 36:101374

20. Kister I, Chamot E, Cutter G, Bacon TE, Jokubaitis VG, Hughes SE et al (2012) Increasing age at disability milestones among MS patients in the MSBase registry. J Neurol Sci 318(1-2):94-99

21. Cree BA, Gourraud PA, Oksenberg JR, Bevan C, CrabtreeHartman E, Gelfand JM et al (2016) Long-term evolution of multiple sclerosis disability in the treatment era. Ann Neurol 80(4):499-510

22. Confavreux C, Vukusic S, Adeleine P (2003) Early clinical predictors and progression of irreversible disability in multiple sclerosis: an amnesic process. Br J Neurol 126(Pt 4):770-782

23. Simonsen CS, Edland A, Berg-Hansen P, Celius EG (2017) High prevalence and increasing incidence of multiple sclerosis in the Norwegian county of Buskerud. Acta Neurol Scand 135(4):412-418

24. Sorensen PS, Sellebjerg F, Hartung HP, Montalban X, Comi G, Tintoré M (2020) The apparently milder course of multiple sclerosis: changes in the diagnostic criteria, therapy and natural history. Br J Neurol 143(9):2637-2652

25. Kaufmann M, Kuhle J, Puhan MA, Kamm CP, Chan A, Salmen A et al (2018) Factors associated with time from firstsymptoms to diagnosis and treatment initiation of Multiple Sclerosis in Switzerland Multiple sclerosis. J Exper Trans Clin 4(4):2055217318814562

26. Capra R, Cordioli C, Rasia S, Gallo F, Signori A, Sormani MP (2017) Assessing long-term prognosis improvement as a consequence of treatment pattern changes in MS. Multiple Sclerosis (Houndmills, Basingstoke, England) 23(13):1757-1761

27. Schumacher GA, Beebe G, Kibler RF, Kurland LT, Kurtzke JF, McDowell F et al (1965) Problems of experimental trials of therapy in multiple sclerosis: report by the panel on the evaluation of experimental trials of therapy in multiple sclerosis. Ann N Y Acad Sci 122:552-568

28. Poser CM, Paty DW, Scheinberg L, McDonald WI, Davis FA, Ebers GC et al (1983) New diagnostic criteria for multiple sclerosis: guidelines for research protocols. Ann Neurol 13(3):227-231

29. McDonald WI, Compston A, Edan G, Goodkin D, Hartung HP, Lublin FD et al (2001) Recommended diagnostic criteria for multiple sclerosis: guidelines from the International Panel on the diagnosis of multiple sclerosis. Ann Neurol 50(1):121-127

30. Polman CH, Reingold SC, Banwell B, Clanet M, Cohen JA, Filippi $M$ et al (2011) Diagnostic criteria for multiple sclerosis: 2010 revisions to the McDonald criteria. Ann Neurol 69(2):292-302

31. Polman CH, Reingold SC, Edan G, Filippi M, Hartung HP, Kappos L et al (2005) Diagnostic criteria for multiple sclerosis: 2005 revisions to the "McDonald Criteria." Ann Neurol 58(6):840-846

32. Sormani MP (2009) The Will Rogers phenomenon: the effect of different diagnostic criteria. J Neurol Sci 287(Suppl 1):S46-S49

33. Kaisey M, Solomon AJ, Luu M, Giesser BS, Sicotte NL (2019) Incidence of multiple sclerosis misdiagnosis in referrals to two academic centers. Multiple Sclerosis Related Disord 30:51-56

34. Siva A (2013) Asymptomatic MS. Clin Neurol Neurosurg 115(Suppl 1):S1-5

35. Talley CL (2005) The emergence of multiple sclerosis, 18701950: a puzzle of historical epidemiology. Perspect Biol Med 48(3):383-395

36. Eriksson M, Andersen O, Runmarker B (2003) Long-term follow up of patients with clinically isolated syndromes, relapsingremitting and secondary progressive multiple sclerosis. Multiple Sclerosis (Houndmills, Basingstoke, England) 9(3):260-274 
37. Runmarker B, Andersen O (1993) Prognostic factors in a multiple sclerosis incidence cohort with twenty-five years of follow-up. $\mathrm{Br}$ J Neurol 116(Pt 1):117-134

38. McDonald WI (1989) Diagnosis of multiple sclerosis. BMJ (Clinical research ed) 299(6700):635-637

39. Giovannoni G, Butzkueven H, Dhib-Jalbut S, Hobart J, Kobelt G, Pepper G et al (2016) Brain health: time matters in multiple sclerosis. Multiple Sclerosis Related Disord 9(Suppl 1):S5-s48

40. Dalgas U, Langeskov-Christensen M, Stenager E, Riemenschneider M, Hvid LG (2019) Exercise as medicine in multiple sclerosistime for a paradigm shift: preventive, symptomatic, and diseasemodifying aspects and perspectives. Curr Neurol Neurosci Rep 19(11):88

41. Roth GA, Johnson CO, Abate KH, Abd-Allah F, Ahmed M, Alam $\mathrm{K}$ et al (2018) The burden of cardiovascular diseases among US States, 1990-2016. JAMA Cardiol 3(5):375-389

42. Global, regional, and national disability-adjusted life-years (DALYs) for 333 diseases and injuries and healthy life expectancy (HALE) for 195 countries and territories, 1990-2016: a systematic analysis for the Global Burden of Disease Study 2016. Lancet (London, England). 2017;390(10100):1260-344.

43. Schoeni RF, Freedman VA, Martin LG (2008) Why is late-life disability declining? The Milbank quarterly $86(1): 47-89$

44. Rosso M, Chitnis T (2020) Association between cigarette smoking and multiple sclerosis: a review. JAMA Neurol 77(2):245-253

45. Smoking prevalence and attributable disease burden in 195 countries and territories (2017) 1990-2015: a systematic analysis from the Global Burden of Disease Study 2015. Lancet (London, England) 389(10082):1885-1906

46. Marcon A, Pesce G, Calciano L, Bellisario V, Dharmage SC, Garcia-Aymerich J et al (2018) Trends in smoking initiation in Europe over 40 years: a retrospective cohort study. PLoS ONE 13(8): 0201881

47. Sintzel MB, Rametta M, Reder AT (2018) Vitamin D and multiple sclerosis: a comprehensive review. Neurol Ther 7(1):59-85

48. Ascherio A, Munger KL, Simon KC (2010) Vitamin D and multiple sclerosis. Lancet Neurol 9(6):599-612

49. Zhang Y, Salter A, Wallstrom E, Cutter G, Stuve O (2019) Evolution of clinical trials in multiple sclerosis. Thera Adv Neurol Disord 12:1756286419826547

50. Giovannoni G, Comi G, Cook S, Rammohan K, Rieckmann P, Soelberg Sorensen P et al (2010) A placebo-controlled trial of oral cladribine for relapsing multiple sclerosis. En J Med 362(5):416-426

51. The IFNB Multiple Sclerosis Study Group and The University of British Columbia MS/MRI Analysis Group (1995) Interferon beta- $1 \mathrm{~b}$ in the treatment of multiple sclerosis: final outcome of the randomized controlled trial. Neurology 45(7):1277-1285

52. Kappos L, Radue EW, O'Connor P, Polman C, Hohlfeld R, Calabresi P et al (2010) A placebo-controlled trial of oral fingolimod in relapsing multiple sclerosis. En J Med 362(5):387-401

53. Sormani MP, Bruzzi P (2015) Can we measure long-term treatment effects in multiple sclerosis? Nat Rev Neurol 11(3):176-182 